Research Paper

\title{
Learning Logic Gate through 7-Gates
}

\section{Hanasrullah Halim ${ }^{1}$, Wan Amirah Najwa Wan Idris ${ }^{1}$, Haslina Hassan ${ }^{1}$, Ismail Yusuf Panessai $^{1}$}

${ }^{1}$ Program of Game Development, Department of Computing, Faculty of Arts, Computing, and Industry Creative. Universiti Pendidikan Sultan Idris, Malaysia.

Article History

Received:

14.07.2019

Revised:

20.01.2020

Accepted:

19.02 .2020

*Corresponding Author:

Ismail Yusuf Panessai

Email:

ismailyusuf@fskik.upsi.edu.my

This is an open access article, licensed under: $\mathrm{CC}-\mathrm{BY}-\mathrm{SA}$
Abstract: This game is a simple method for a student that try to learn in Logic Gates, an educational game with futuristic adventure. The only way for the player to save the digital world in this game by using Logic Gates, with Logic Gates formulas the player can make the power connection on the circuit to the digital world engine. Without knowing how Logic Gates functional will make the player losing the power for the engine to the digital world. 7 Gates Digital World is a complex genre game. The main genre for this game absolutely is an Educational Game. Although, the game developer made a complex genre for this educational game. Puzzle include in this game combined with platforms games style the player must collect all the switches in confusion platform map to go through the next portal to the next level. Educational genre in this game giving the content level completely based on the level of understanding and give the player to memorize every gates formula.

Keywords: Educational Game, Instructional Technology, Logic Gate. 


\section{Introduction}

This game is a simple method for student that try to learn in Logic Gates, an educational game with futuristic adventure. Making this game absolutely has the aim for the future especially in education. In fact, nowadays we have involving to further high technologies to all teen generation who struggle in learning about the system in industry 4.0. In certain secondary-school in Malaysia now are started to study about logic gates so as a game designer and developer are looking forward to the teenager and country. There are academic debates as to whether such digitization of organizations can be called the fourth industrial revolution [1] [2] [3].

The 7 gates digital world educational game intended to create a new opportunity to the one who not a bookworm also the person who love in gaming but want to do gaming in benefits sight. Striking the difference in this game, the game developer use a digital circuit theme. Mostly, 7 gates digital world title presented where the user can explore the digital world, in others mean the user wanted to know how it looks like the digital world that the game developer could imagine as a game designer.

This game will present a simulation on starting the game before going to puzzle platform which is the user needs to collect switches to complete every level and answer the logic gates questions. The simulation can be used for teaching and learning especially for a briefing session on how is the 7 logic gates functional. After that, the user can proceed to solve the puzzle on the site of the platform.

Despite, there's a challenge in the puzzle, the user needs to be patient to finish every level, there's no map to guide the user when searching the missing switches. Also, there's a fire whenever player falls into the fire causes Neon died and the current level will be restarted. Every level the game developer create a portal to proceed on the next level, level 1 to level 2, level 2 to level 3, and level 3 to end. Currently, the game developer only made 3 levels if there's no objection or an opportunity to the game developer and the supervisor to innovate 7 gates digital world to be more advanced, the game developer will make it more live for the future.

\section{Synopsis}

Neon, Neon was invented by Professor Yu that known well about the 7 gates function, Professor $\mathrm{Yu}$ created Neon because he knew Digital World need Neon to saved engine to digital world. The character need to save the elementary building block of digital circuit from stopped by fixing the connection of input and output. There's 7 different types of gates can be used in the digital circuit, which are (NOT, AND, OR, NAND, NOR, XOR and XNOR).

\section{Methodology}

The game developer for this game considers the most entertaining game to be welcomed by the audience is an adorable character, especially with storytelling animation. But, game developers have difficulty when creating characters that must be adorable [4] [5]. This game methodology is intended to make educational games with adorable conceptual characters.

\subsection{Genre}

The main genre for this game is an educational game and sub-genre is puzzle and platform [6] [7]. Puzzle include in this game combined with platforms games style the player must collect all the switches in confusion platform map to go through the next portal to the next level. Educational genre in this game giving the content level completely based on the level of understanding and give the player to memorize every gates formula.

\subsection{Target Demographics}

The target audience is the students should be secondary-school and certainly University lecturers and student. This game more to serious game in other mean, this educational game made on purpose to create a difference method to present Logic Gates to the audience. This game can be used as a learning material for training or learning, it's obviously made for 12 years old - 25 years old mostly for both male and female players.

Among the plethora of digital game genres used for educational purposes sits the genre of Digital Card Games (DCGs) that is the modern expression of Card Games (CGs). An educational game used for learning more than this logic gates game. Educational Card Games (CGs), in both physical and digital mode, have been reported for the learning of various subjects, such as: languages, mathematics, science, history, environmental education, health, teacher education, etc [8] [9]. 


\subsection{High Concept}

High concept for this game we made it with content to tell the audience that the game developer focused on logic gates "Save Digital World with Logic Gates Knowledge". Description: The only way for the player to save the digital world in this game by using Logic Gates, with Logic Gates formulas the player can make the power connection on the circuit to the digital world engine. Without knowing how Logic Gates functional will make the player losing the power for the engine to the digital world.

\subsection{Unique Selling Point}

The game has a complex combination platform puzzle an educational game ever for the pc game. The new way to learn Logic Gates especially in gaming experience for the students nowadays.

Involving students in practice in the game to adopt new ways to become and worldview, games can be the website of individual transformation, encourages students to think of themselves in terms of education roles like scientists or policymakers [10].

\subsection{Game Mechanics}

The mechanics pitched are all from digital games the game developer supported develop they are coded into the game. None of these mechanics are explicitly declared for the player. But players can often think out what the mechanic is as they play the game.

- The first mechanics is a level remains locked till a player successfully completes the current level.

- Secondly, when players give an incorrect answer to the question they get can't continue until they figured out.

- This is followed by an opportunity to re-try answering the question and get the learning processes.

- Next, once the player collected all the switches the player can proceed to the next level otherwise the portal to next level won't function.

Likewise, the level will be restarted on the current level if the player falls down to on fire (fire only available on level 2 and level 3) because of the player died.

\subsection{Platforms and Minimum Specifications}

The minimum specifications for the PC System:

- OS: 32-bit Windows 7.

- CPU: Intel Core i3-6300 3.8GHz / AMD FX-4350 4.2 GHz Quad-Core Processor.

- RAM: $256 \mathrm{MB}$.

- GPU: AMD Radeon Xpress 1200 Series or NVIDIA GeForce FX 5200.

- HARD DRIVE: Minimum 300MB of free space.

\section{Storyline}

Story plot is a literary term used to describe the events that make up a story, or the main part of a story [11]. These events relate to each other in a pattern or a sequence. The structure of a novel depends on the organization of events in the plot of the story.

\subsection{Outline and Plot}

The digital world is the universe which exists in the digital like the video game on the website or internet. The digital world lives because of the engine that keep strolling electric energy.

Once upon times, the engine has gone wrong and the digital world community don't know what happened and can't figure out how to get over the current situation. Yet, Professor Yu who the old occupant on the digital world has the idea to create a robot that can solve the breakdown engine to the digital world. After the robot has been invented Professor Yu named the robot Neon, so Neon was invented by Professor Yu with the knowledge to solve all of the 7 gates function. Only Neon could save the elementary building block of the digital circuit from stopped by fixing the connection of input and output. There are 7 different types of gates can be used in the digital circuit (NOT, AND, OR, NAND, NOR, XOR and XNOR). 

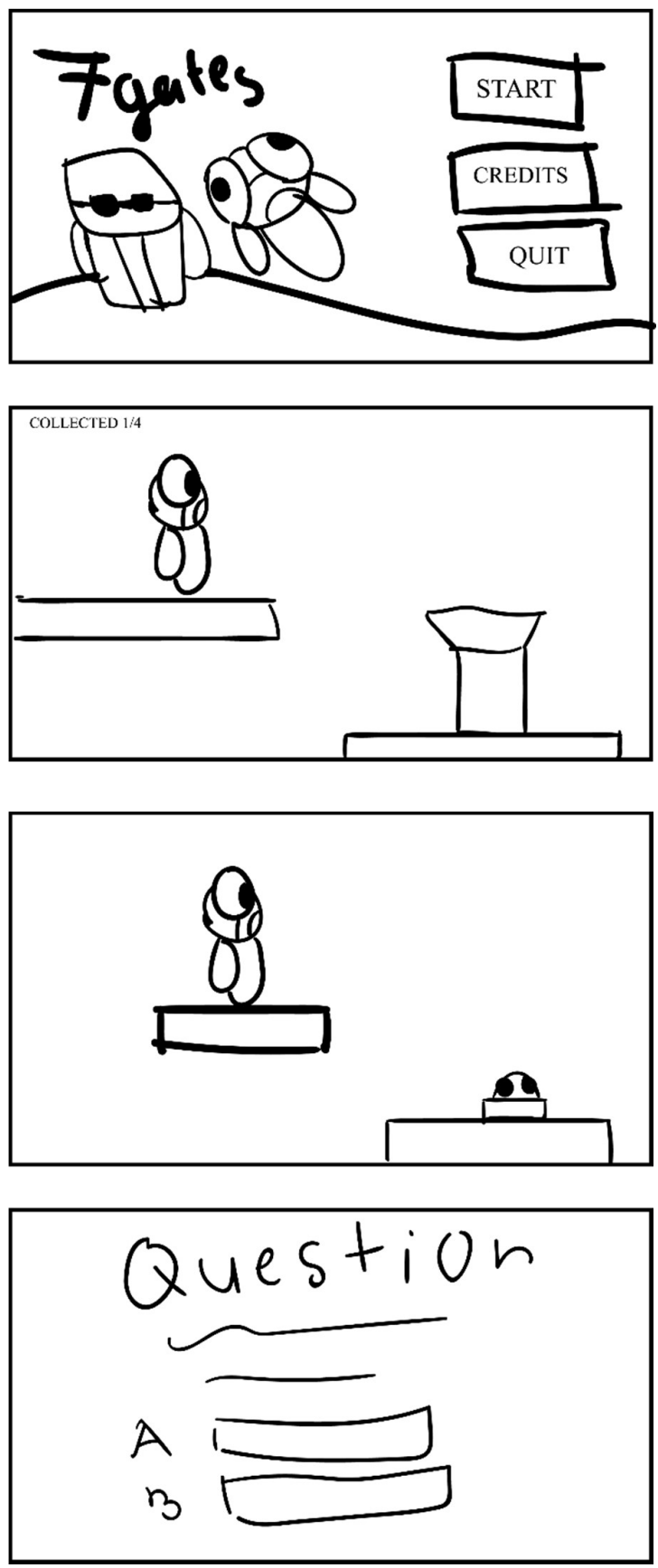

Figure 1. Storyboard

\subsection{Storyboard}

Storyboard is a sequence of drawings, typically with some directions and dialogue, representing the shots planned for a film or television production. 


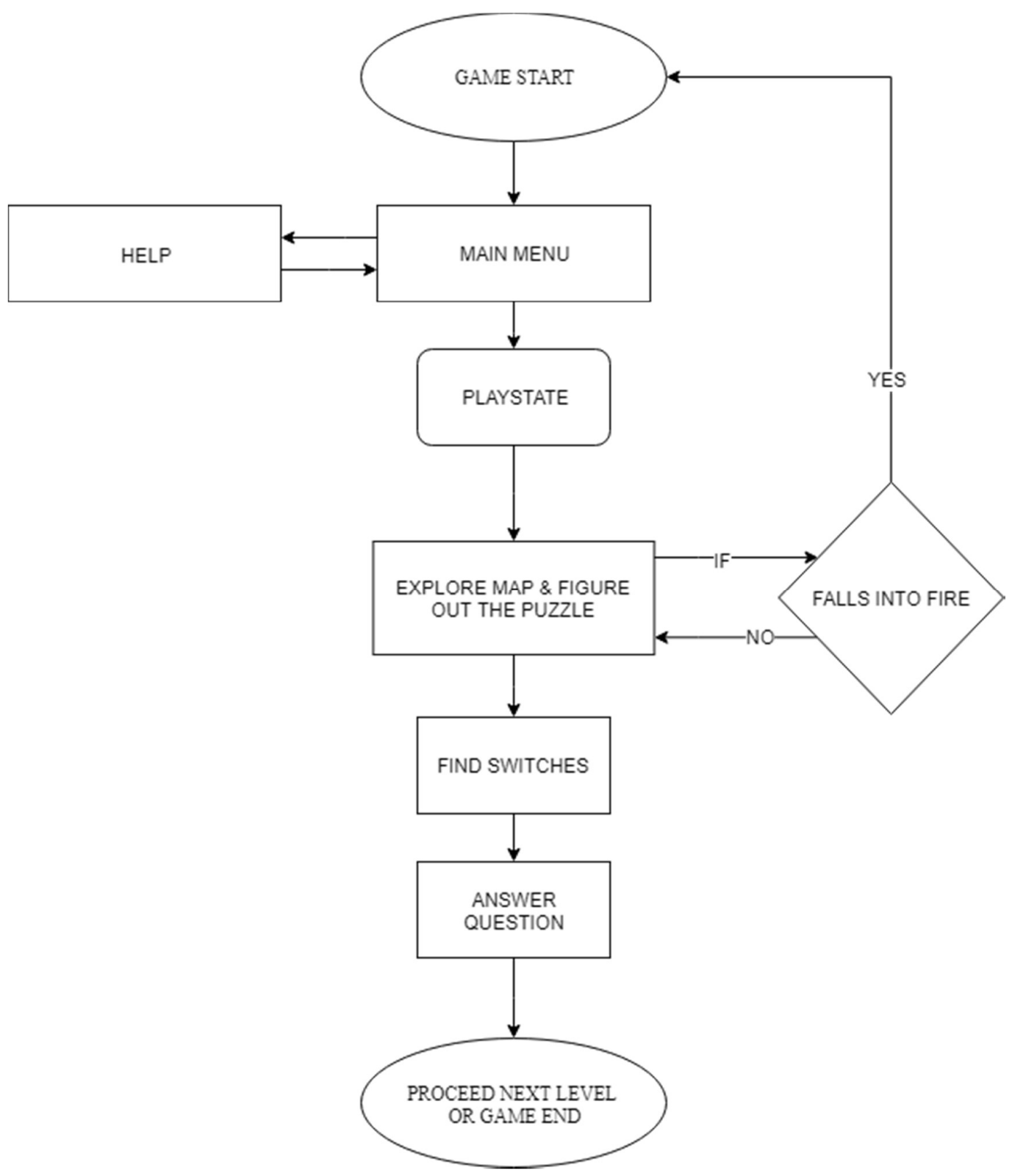

Figure 2. Game Flow Diagram 


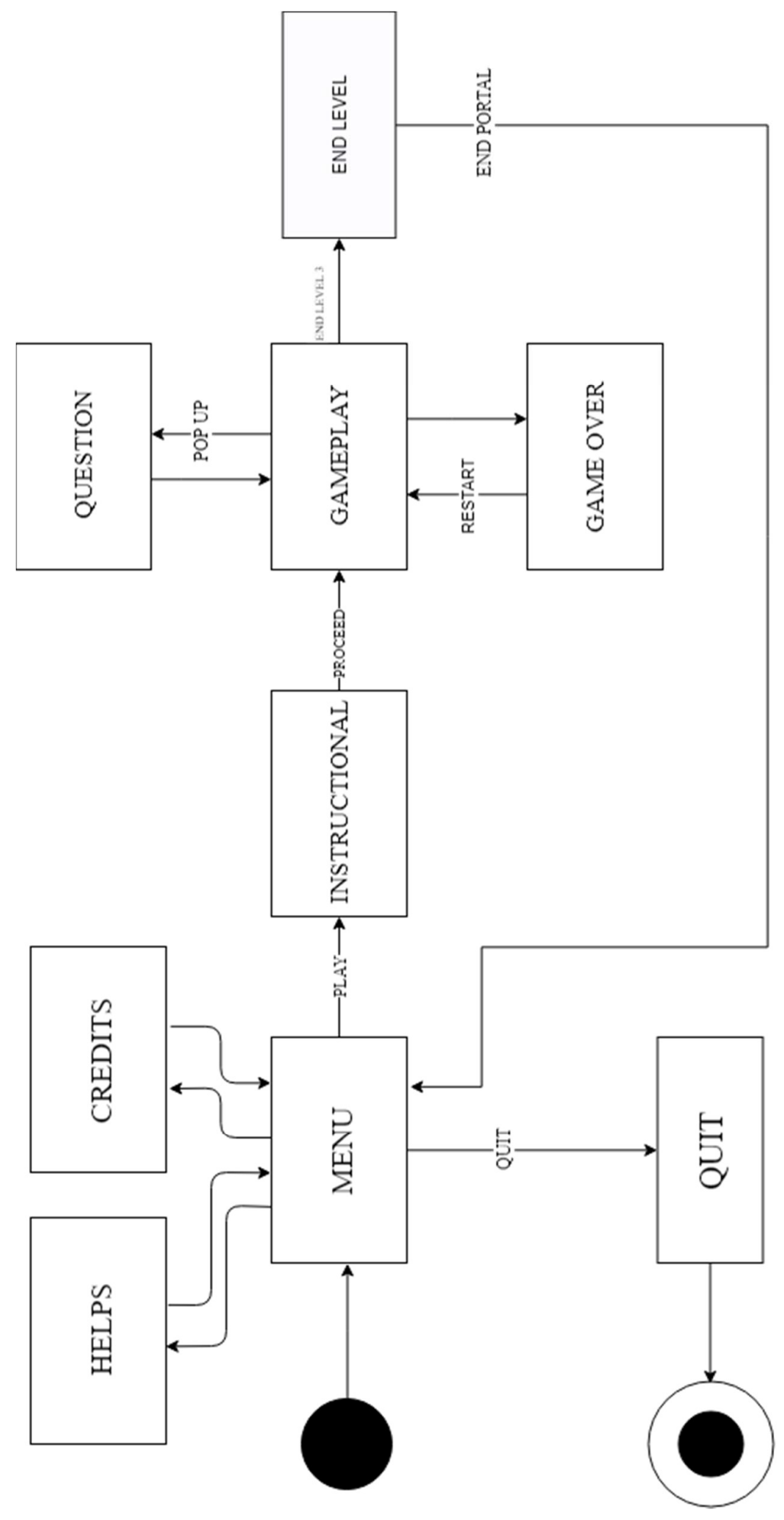

Figure 3. Screen Flow Diagram

\section{Game Design}

Game design is the art of applying design and aesthetics to create a game for entertainment or for educational, exercise, or experimental purposes. Increasingly, elements and principles of game design are also applied to other interactions, particularly virtual ones (see gamification). 


\subsection{Concept Art and Art Style}

Game concept art for the 7 Gates Digital World the game developer choose the pixel concept art because it's more realistic to animated and easy to resize and crop.
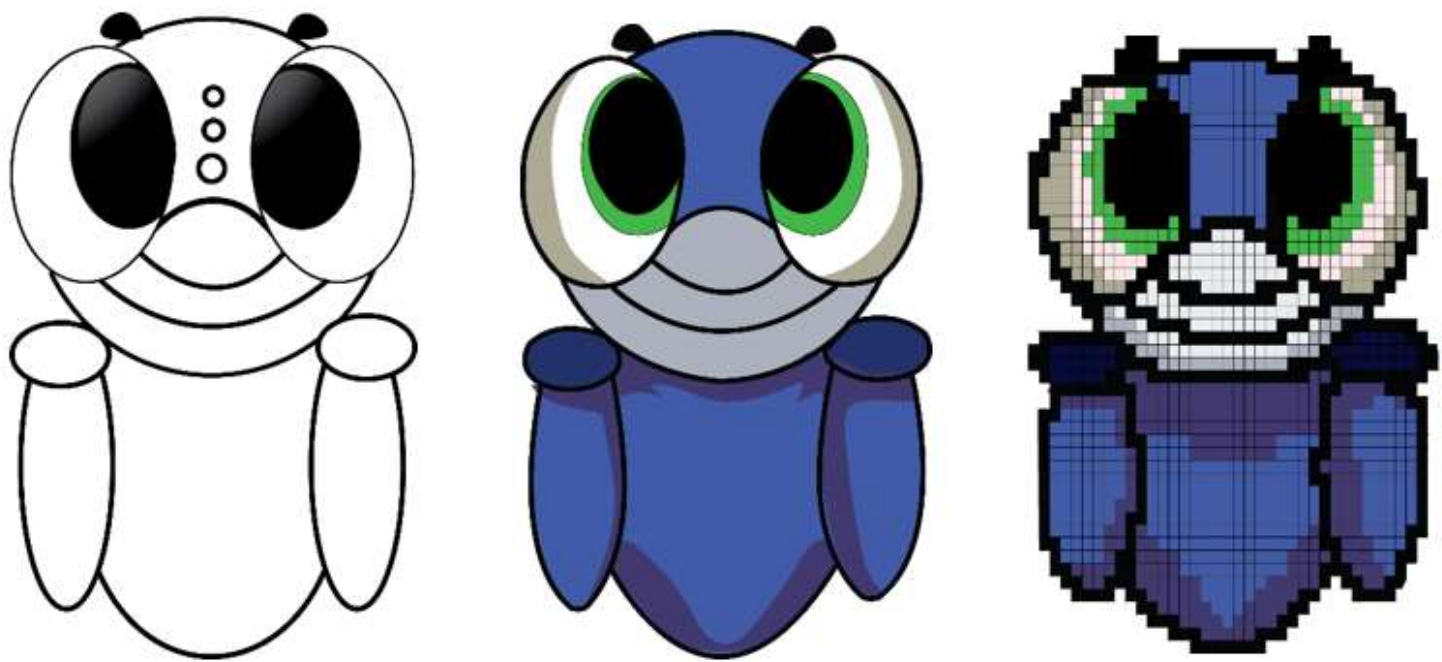

Figure 4. The Main Character Concept

\subsection{Colours}

The most colour can be found in this 7 Gates Digital World game is purple and blue. Therefore, purple is one of nice looking colours, as assigned or mark symbolic to the game is the most colour is favourite colour will be inside the game. Meanwhile, the blue colour is the representative to the digital world and one of the colours of a component in the digital circuit in logic gates content.

\subsection{Characters Design}

The main character in this game is NEON, the only character player will be controlled to save the digital world engine from stopping.
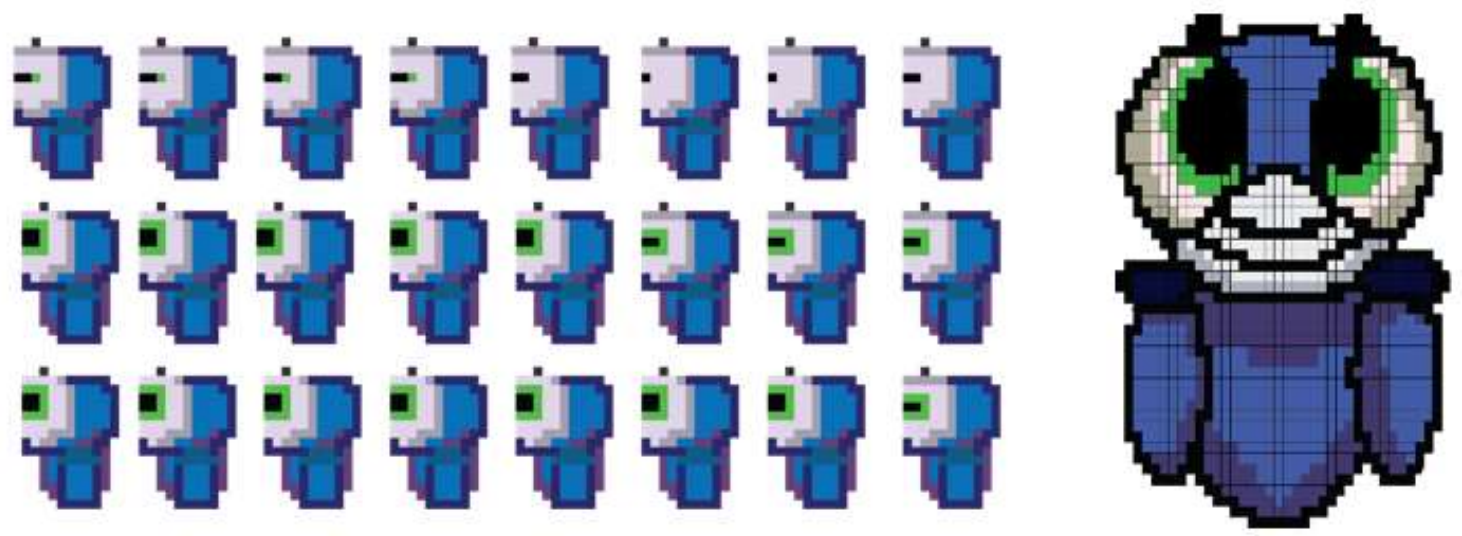

Figure 6. Neon Animation

The creator to NEON, Professor Yu who the old occupant on the digital world has the idea to create a robot that can solve the breakdown engine to the digital world. 


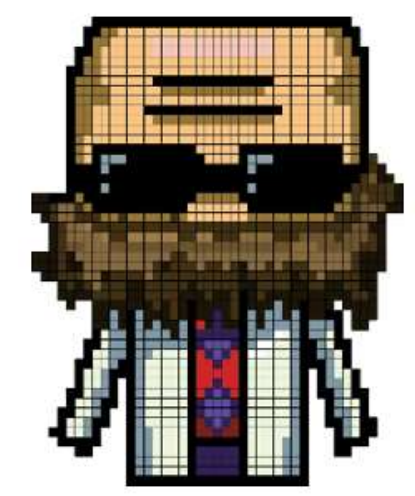

Figure 7. Professor Yu

\subsection{Environment and Scene Design}

There are some scenes design:

- Menu: Help

- Tips Pop-up

- Question Pop Up

- 1 st Level Portal

- 2nd Level Portal

- 3rd Level Portal

- 1 st Level Environment

- 2nd Level Environment

- 3rd Level Environment

- Simulation Instruction

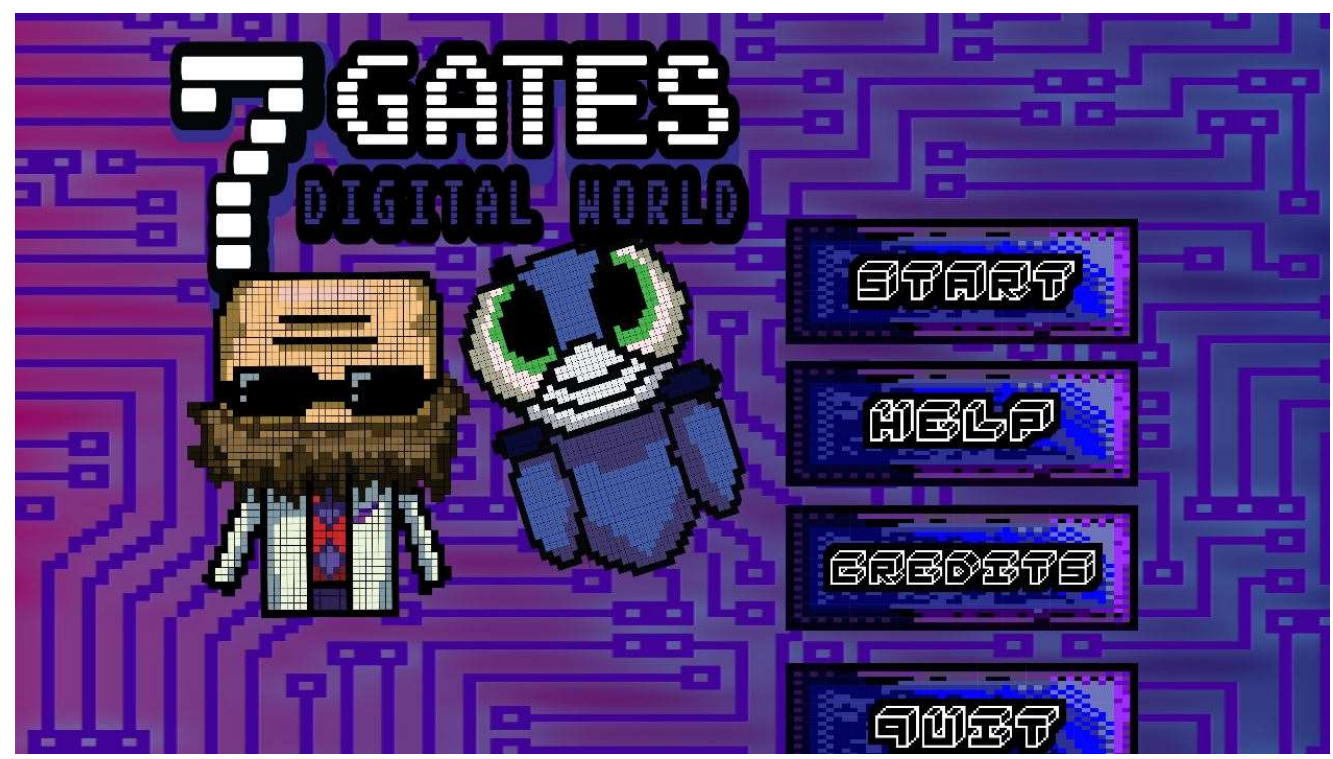

Figure 8. Main Menu 


\section{Testing}

Game testing, a subset of game development, is a software testing process for quality control of video games. The primary function of game testing is the discovery and documentation of software defects (aka bugs). Interactive entertainment software testing is a highly technical field requiring computing expertise, analytic competence, critical evaluation skills, and endurance. In recent years the field of game testing has come under fire for being excessively strenuous and unrewarding, both financially and emotionally.

\subsection{Bugs, Issue and Constraints}

The game bug in this games, in level one bug is when the user jump over to the portal axis then the user will be stuck right there and there's no way to go up again. Second, the game bug happened on level 2 randomly in the exhibition. The bug on level 2 is the collected switches already started with complete collected counted and causing the player will stuck on the level 2 in another way is close the game using task manager to end the 7 gates digital world task.

\subsection{Gamers Feedbacks}

The gamer feedbacks for this game mostly said it was a boring game when it comes to learning about the content inside the gameplay to end every level. Even so, there's a few a positive feedback is the game content completely achieve the idea goal on obtaining this game as an educational game and it will be useful in academic.

\section{Conclusions}

There are many unexpected features in the making of this game. Firstly, this game should be a mobile game because the supervisor and the developer are planning to give a new touch to the user helping education growth smoothly for the future. Second, this game features doesn't have a platform genre, after week 8 in the making of 7 gates digital world the game developer have changed the idea because there are possibilities to go further if the game has complex genre and features.

After the game developer were done made the 7 gates digital world game and preview it in the exhibition, the problem the game developer faced in the way long before the game developer made it is much more than expected. The first problem is finding out coding to make new scripts, the solution found on week 5-6 in Unity Forum and a few game designer and development websites.

There's a suggestion we got in the exhibition, to innovate the 7 gates digital world education game. First suggestion is from Mr. Jason from KDU, the question need to remove and make a puzzle on how to on the switches with 7 difference gates which is it was our idea that we have tried but can't make the coding for that. Next, a suggestion to create an animation or intro when the game started. Indeed, every game has a story to tell that's why a lecturer gives suggestion to give life, give emotion and the curiosity to the audience to explore more about 7 gates digital world. After that, some of others students give a suggestion to put more animation on character movement especially for Neon, the game developer already put an animation but the animation just an idle animation because the game developer can't make it in time for animation a story-telling for 7 gates digital world.

The suggestion for animation is when Neon jumping, Neon falls died, and moving animation.

\section{References}

[1] A. P. Michael, and P. Jandrić, Education and Technological Unemployment in the Fourth Industrial Revolution. Oxford: The Oxford Handbook of Higher Education Systems and University Management, 2019.

[2] N. N. M. Kamal, A. H. M. Adnan, A. A.Yusof, M. K. Ahmad, and M. A. M. Kamal, "Immersive Interactive Educational Experiences - Adopting Education 5.0, Industry 4.0 Learning Technologies for Malaysian Universities," in MNNF Network (Ed.), Proceedings of the International Invention, Innovative \& Creative (InIIC) Conference. pp. 190-196, 2019.

[3] O. C. Hee, and K. Vimalathithan, "Thought Leadership in the Education Industry: A Review," International Journal of Academic Research in Business \& Social Sciences, vol. 9, no. 4, 2019. doi: 10.6007/IJARBSS/v9-i4/5809.

[4] E. Zell, K. Zibrek, and R. McDonnell, "Perception of virtual characters," SIGGRAPH '19 - ACM SIGGRAPH 2019, pp.1-17, 2019. doi: 10.1145/3305366.3328101 
[5] J. A. Bopp, L. J. Müller, L. F. Aeschbach, K. Opwis, and E. D. Mekler, "Exploring Emotional Attachment to Game Characters," SIGGRAPH '19: ACM SIGGRAPH 2019," pp.18-25, 2019. doi: $10.1145 / 3305366.3328101$

[6] S. J. Ahn, and J. N. Bailenson, "Self-endorsing versus other-endorsing in virtual environments: The effect on brand preference," Journal of Advertising, pp. 2753-2763, 2011.

[7] M. V. Birk, C. Atkins, J. T. Bowey, and R. L. Mandryk, "Fostering intrinsic motivation through avatar identification in digital games," in Proceedings of the 2016 CHI Conference on Human Factors in Computing Systems- ACM, pp. 2982--2995, 2016. doi:10.1145/2858036.2858062.

[8] E. Adams, Fundamentals of Game Design. Pearson Education, 2014.

[9] M. J. Gaydos, "Developing a geography game for Singapore classrooms," in the International Conference of the Learning Sciences (ICLS), vol. 2, transforming learning, empowering learners, C.-K. Looi, J. L. Polman, U. Cress, \& P. Reimann (Eds.), Singapore: International Society of the Learning Sciences, 2016, pp. 729-736.

[10] S. Barab, P. Pettyjohn, M. Gresalfi, C. Volk, and M. Solomou, "Game-based curriculum and transformational play: Designing to meaningfully positioning person, content, and context," Computers \& Education, vol. 58, no. 1, pp. 518-533, 2012. doi:10.1016/j.compedu.2011.08.001.

[11] F. Peinado, and P. Gervás, "Transferring Game Mastering Laws to Interactive Digital Storytelling," in Technologies for Interactive Digital Storytelling and Entertainment, vol 3105, Göbel S. (Ed.), Springer, Berlin, Heidelberg, 2004. 